\title{
El derecho fundamental al secreto de las comunicaciones
}

\author{
F. Javier Díaz Revorio*
}

\section{Introducción: significado y fundamento constitucional del derecho al secreto de las comunicaciones}

Existe una garantía que protege las comunicaciones entre las personas, de manera que cualquier supuesto admisible de interceptación de las mismas se presenta como excepcional, y rodeado de límites, requisitos y garantías, dado que esa práctica afecta a un derecho fundamental, y solo el cumplimiento de esos requisitos y garantías permitirá que esa afectación no se convierta en vulneración.

Como derecho fundamental, el secreto de las comunicaciones encuentra reconocimiento en la Declaración Universal de Derechos Humanos del 10 de diciembre de 1948 (artículo 12) y en algunos tratados internacionales ratificados por España — que poseen efectos interpretativos sobre nuestros derechos constitucionales, según el artículo 10, inciso 2 de la norma fundamental-, como el Pacto Internacional de Derechos Civiles y Políticos del 19 de diciembre de 1966 (artículo 17), o el Convenio de Roma del 4 de noviembre de 1950, para la protección de los Derechos Humanos y de las Lib|ertades Fundamentales (artículo 8). Si bien estos textos prefieren referirse al respeto a la correspondencia - término que en sentido amplio debe entenderse equiparablePor su parte, el artículo 7 de la Carta de los Derechos Fundamentales de la Unión Europea - luego incorporado a la Constitución europea como artículo II-67-, afirma, en términos similares, que «[...] toda persona tiene derecho al respeto de su vida privada y familiar, de su domicilio y del secreto de sus comunicaciones».

Profesor titular de Derecho Constitucional en la Universidad de Castilla-La Mancha, Toledo (España). 
En la misma línea, la Constitución española señala en su artículo 18, inciso 3: «Se garantiza el secreto de las comunicaciones, y en especial, de las postales, telegráficas y telefónicas, salvo resolución judicial».

El correcto entendimiento del significado de este derecho requiere relacionarlo con los restantes derechos del artículo 18, todos los cuales parecen tener un fundamento común, como es la protección de la vida privada o privacidad de la persona en su ámbito estrictamente personal o en su esfera más próxima. En esta línea, es particularmente evidente la vinculación entre el secreto de las comunicaciones y la intimidad personal y familiar, reconocida en el artículo 18, inciso 1, pues en definitiva el secreto de las comunicaciones pretende proteger la comunicación entre personas en la distancia, aproximándola a lo que sería una comunicación directa, y garantizando en todo caso una comunicación privada. En esta línea, en la STC 123/2002, de 20 de mayo, f. j. 5, se afirma que «[...] el fundamento del carácter autónomo y separado del reconocimiento de este derecho fundamental y de su específica protección constitucional reside en la especial vulnerabilidad de la confidencialidad de estas comunicaciones en la medida en que son posibilitadas mediante la intermediación técnica de un tercero ajeno a la comunicación». Con todo, esta relación entre ambos derechos no impide una necesaria delimitación entre el contenido y sentido constitucional de los mismos, que viene dada sobre todo por la configuración del secreto de las comunicaciones como garantía formal -independiente del contenido-, y por la reserva absoluta de resolución judicial para levantar esta garantía, como características específicas de este derecho que no se predican en cambio de la intimidad — véase la mencionada STC 123/2002-.

El Tribunal Constitucional, interpretando este derecho, ha apuntado a la libertad de las comunicaciones como presupuesto o contenido implícito del mismo:

Rectamente entendido, el derecho fundamental [al secreto de las comunicaciones] consagra la libertad de las comunicaciones, implícitamente, y de modo expreso, su secreto, estableciendo en este último sentido la interdicción de la interceptación o del conocimiento antijurídico de las comunicaciones ajenas. El bien constitucionalmente protegido es así — a través de la imposición a todos del «secreto»— la libertad de las comunicaciones, siendo cierto que el derecho puede conculcarse tanto por la interceptación en sentido estricto (que suponga aprehensión física del soporte del mensaje — con conocimiento o no del mismo - o captación, de otra forma, del proceso de comunicación) como por el simple conocimiento antijurídico de lo comunicado (apertura de la correspondencia ajena guardada por su destinatario, por ejemplo). (STC 114/1984, de 29 de noviembre, f. j. 7, muy reiterada posteriormente). 


\section{Titularidad del derecho}

Cualquier análisis de un derecho fundamental debe tener en cuenta el problema de su titularidad, es decir, de quién o quiénes se predica constitucionalmente el derecho, a quienes se les reconoce. En el caso del secreto de las comunicaciones, tratándose de un derecho de la esfera privada, vinculado directamente a la dignidad humana, la titularidad debe recaer en toda persona, con independencia de su nacionalidad, y por lo tanto no cabe establecer excepciones, privaciones o limitaciones específicas para el caso de los extranjeros.

Por otro lado, hay que plantear la cuestión de la titularidad de este derecho por parte de las personas jurídicas. Si bien su condición de derecho de la persona en el sentido visto podría generar dudas de esta titularidad, lo cierto es que, paralelamente a lo que ha sucedido con otros derechos de la esfera privada, como la inviolabilidad del domicilio, la jurisprudencia y la doctrina han coincidido en señalar que las personas jurídicas son titulares también del derecho al secreto de las comunicaciones. Obviamente, este entendimiento, que es comúnmente aceptado, implica una cierta interpretación extensiva o en sentido figurado, pues obviamente la persona jurídica no puede mantener comunicaciones si no es a través de la mediación de personas físicas, que son quienes realmente ejecutarán los actos necesarios para llevar a cabo esa comunicación. En todo caso, se reconoce el derecho a la persona jurídica que formal y jurídicamente esté llevando a cabo la comunicación, aunque no hay que excluir que en una misma comunicación se dé una concurrencia de titularidades. Así, por ejemplo, en una comunicación telefónica de una persona jurídica y en nombre de esta, se protege el derecho tanto de dicha persona jurídica como de la persona física que efectivamente se comunica.

Más dudoso es el problema de si la titularidad del derecho debe reconocerse también a las personas jurídico-públicas. Aunque no hay acuerdo sobre este particular, y hay que reconocer que en principio los derechos fundamentales tienen el sentido de proteger a las personas en sus relaciones con el Estado o con otras personas, creo que puede emplearse el mismo razonamiento utilizado con las personas jurídico-privadas para proteger a las personas de derecho público en las comunicaciones que puedan formalmente mantener, sin perjuicio de la garantía que también tienen las personas físicas que efectivamente ejecutan la comunicación.

\section{3. Ámbito protegido}

La delimitación concreta del ámbito constitucionalmente protegido por el derecho fundamental al secreto de las comunicaciones plantea no pocos aspectos dudosos, que sin embargo se han ido resolviendo en buena medida por la 
jurisprudencia. Estas cuestiones afectan particularmente a los medios, elementos y contenidos que efectivamente se protegen.

Hay que comenzar por señalar que el secreto de las comunicaciones constituye una garantía objetiva, que protege cualquier comunicación con independencia de su contenido, es decir, tanto si se trata de una comunicación referida a aspectos íntimos, como si tiene por objeto cualquier otra cuestión, aunque sea intrascendente. Según ha señalado el Tribunal Constitucional, «[...] el concepto de secreto en el artículo 18, inciso 3, tiene un carácter formal, en el sentido de que se predica de lo comunicado, sea cual sea su contenido y pertenezca o no el objeto de la comunicación misma al ámbito de lo personal, lo íntimo o lo reservado». Hay, en los términos utilizados por el Tribunal, una "[...] presunción iuris et de iure de que lo comunicado es secreto» (STC 114/1984, del 29 de noviembre).

Pero lo protegido por el derecho no es solo el contenido de la comunicación, sino también el soporte de la misma, y las circunstancias que la rodean. La protección constitucional se proyecta sobre el proceso de comunicación mismo cualquiera que sea la técnica utilizada (STC 70/2002, del 3 de abril). En particular, queda comprendida la protección de la propia identidad subjetiva de los interlocutores (sentencia del Tribunal Europeo de Derechos Humanos -TEDH del 2 de agosto de 1984, caso Malone contra el Reino Unido, SSTC 114/1984, ya citada, y 123/2002, del 20 de mayo), si bien la injerencia consistente en la entrega de los listados de las llamadas de una persona por las compañías telefónicas es de menor intensidad que las escuchas telefónicas, lo que permite que la resolución judicial que la autorice sea excepcionalmente una providencia, integrada por la solicitud a la que se remite (STC 123/2002, del 20 de mayo). En suma, lo que interesa destacar es que el secreto de las comunicaciones protege, como se ha dicho, una idea más amplia como es la libertad de las comunicaciones, que engloba el hecho de la comunicación en sí y sus diversas circunstancias, así como el contenido de la misma.

En cuanto a los medios protegidos, ya hemos apuntado que algunos textos internacionales hablan de correspondencia, mientras que la Constitución española se refiere a comunicaciones, en especial, las postales, telegráficas y telefónicas. En realidad, esta enumeración es, como fácilmente puede deducirse, meramente ejemplificativa, de modo que lo que realmente protege la Constitución - y en sentido similar debe entenderse el término utilizado por los convenios internacionales - son todos los medios de comunicación conocidos en el momento de aprobarse la norma fundamental, así como los que han ido apareciendo o puedan aparecer en el futuro. Así, podríamos mencionar el correo postal, el telégrafo, el teléfono fijo o móvil, el télex, el fax, el correo electrónico, la videoconferencia, etcétera. En todo caso, es necesario que exista algún medio para que entre en juego el secreto de las comunicaciones, de manera que 
este derecho no protege la conversación directa entre dos personas — si bien esta, según el caso, podría estar protegida por el derecho a la intimidad-. Por otro lado, el medio utilizado debe ser apto para permitir una comunicación secreta entre varias personas, y por ello están excluidos los medios de comunicación de masas como la radio y la televisión, y en cambio quedan incluidos medios que permiten una conversación entre más de dos personas, pero cerrada o con disponibilidad para aceptar nuevos interlocutores, como la multiconferencia o la videoconferencia.

Con todo, han de tenerse en cuenta las peculiaridades de los diversos medios, que vienen a plantear algunos supuestos de comunicación algo más abierta, o que plantean dudas por diversos motivos. Así, por ejemplo, una tarjeta postal incorpora un texto no cerrado, y con el mismo nivel de accesibilidad que la dirección del destinatario - aunque no por ello deja de estar protegida por el secreto de las comunicaciones-; el uso del telégrafo requiere que, además de los partícipes, al menos dos personas más —el funcionario o trabajador encargado de transmitirlo, y el encargado de recibirlo- conozcan el contenido de la comunicación, aunque estos están obligados por el secreto y deberán guardar la correspondiente reserva. De manera análoga, la empresa que proporciona el servicio de correo electrónico - que eventualmente puede ser una empresa que facilita este servicio a sus trabajadores- emplea un servidor propio por el que transitan todos los correos electrónicos de los clientes o trabajadores, aunque obviamente esta posibilidad de acceso no le legitima para conocer, divulgar o utilizar los contenidos de las comunicaciones. Algunos de los más modernos medios técnicos permiten una comunicación muy abierta y se sitúan casi en la frontera con los medios de masas, como sucede con una videoconferencia en la que el receptor esté constituido por un conjunto indeterminado o abierto de personas en la sala donde se proyecte la imagen y la voz. En fin, aunque el secreto de las comunicaciones no incluye el envío de mercancías, el paquete postal, bien sea enviado a través del servicio de correos o por mensajería privada, es también vía idónea para transmitir cualquier tipo de mensaje o comunicación, que sí deben quedar protegidos, sin que quepa diferenciar a priori el contenido; de ahí que la jurisprudencia más reciente tienda a incluirlos en el ámbito de la garantía constitucional — por ejemplo, SSTS del 26 de junio de 1993 y del 2 de junio de 1997-.

En cuanto a los sujetos sometidos a la garantía del secreto de las comunicaciones, estos serían todos los terceros ajenos a la comunicación, tanto si se trata del Estado o de agentes públicos, como de otros particulares. Sin embargo, el secreto no afecta a los propios partícipes de la comunicación, sin perjuicio de que en ciertos supuestos estos podrían llegar a vulnerar el derecho a la intimidad de su comunicante. El Tribunal Constitucional lo ha afirmado de forma clara: 
No hay «secreto» para aquel a quien la comunicación se dirige, ni implica contravención de lo dispuesto en el artículo 18.3 de la Constitución la retención, por cualquier medio, del contenido del mensaje [...]. Quien entrega a otro la carta recibida o quien emplea durante su conversación telefónica un aparato amplificador de la voz que permite captar aquella conversación a otras personas presentes no está violando el secreto de las comunicaciones, sin perjuicio de que estas mismas conductas, en el caso de que lo así transmitido a otros entrase en la esfera «íntima» del interlocutor, pudiesen constituir atentados al derecho garantizado en el artículo 18.1 de la Constitución. (STC 114/1984, de 29 de noviembre, f. j. 7).

\section{Las excepciones al ámbito constitucionalmente protegido: supuestos y requisitos para la interceptación legítima de las comunicaciones}

Como acabamos de analizar, el secreto de las comunicaciones es un derecho fundamental y una garantía constitucional, de modo que la interceptación de las comunicaciones resultaría en principio una vulneración de ese derecho. Sin embargo, tanto la Constitución española — que garantiza el secreto salvo resolución judicial -, como el Convenio de Roma, reconocen la posibilidad de ciertas injerencias legitimas en el mismo derecho, configurando así la interceptación de las comunicaciones como una eventualidad posible en ciertos supuestos. Con todo, es importante reiterar que la interceptación aparece como la excepción frente al derecho fundamental, que es la regla, y como tal excepción está sometida a límites y requisitos que en todo caso deben cumplirse, y debe ser interpretada y aplicada de forma restrictiva. Estos requisitos, que han sido ampliamente desarrollados por la jurisprudencia del Tribunal Europeo de Derechos Humanos (TEDH), del Tribunal Constitucional y del Tribunal Supremo, giran en torno a varias exigencias fundamentales: la previsión legal, el fin legítimo, la necesidad en una sociedad democrática, y la resolución judicial, si bien de cada una de ellas derivan sus propios requisitos. Las tres primeras derivan fundamentalmente de la redacción del artículo 8 del Convenio Europeo para la Protección de los Derechos Humanos y las Libertades Fundamentales $(\mathrm{CEDH})$, que conviene en este momento transcribir en su integridad:

1. Toda persona tiene derecho al respeto de su vida privada y familiar, de su domicilio y de su correspondencia.

2. No podrá haber injerencia de la autoridad pública en el ejercicio de este derecho, sino en tanto en cuanto esta injerencia esté prevista por la ley y constituya una medida que, en una sociedad democrática, sea necesaria para la seguridad nacional, la seguridad pública, el bienestar económico 
del país, la defensa del orden y la prevención del delito, la protección de la salud o de la moral, o la protección de los derechos y las libertades de los demás.

\subsection{La previsión legal y sus requisitos}

Si bien la Constitución española no señala expresamente que solo una ley puede prever los supuestos de interceptación legítima de las comunicaciones, partiendo de que esa intervención es posible por resolución judicial, cabe entender que esta resolución deberá encontrar fundamento legal; por lo demás, el artículo 53, inciso 1, señala con carácter general que «sólo por ley» puede regularse el ejercicio de los derechos y libertades del capítulo segundo del título I, entre los que se encuentra el secreto de las comunicaciones. El propio Tribunal Constitucional ha señalado que «[...] toda injerencia estatal en el ámbito de los derechos fundamentales y las libertades públicas [...] precisa una habilitación legal» (entre otras, SSTC 49/1999, del 5 de abril, f. j. 4, y 184/2003, del 23 de octubre).

Pero en todo caso, el requisito de la previsión legal es mucho más expreso en el Convenio de Roma, y ha sido detallado en todas sus exigencias por la jurisprudencia del Tribunal Europeo de los Derechos Humanos. De la misma puede deducirse que la previsión legal encierra en realidad tres requisitos, el primero de los cuales afectaría a la previsión en sentido propio, y los otros dos a lo que el Tribunal ha denominado la calidad de la ley (sentencia del 30 de julio de 1997, caso Valenzuela Contreras contra España):

1. La existencia de una base en el derecho interno.

2. La accesibilidad de la ley para la persona implicada.

3. La previsibilidad de la ley en cuanto al sentido y la naturaleza de las medidas aplicables (entre otras, sentencias del TEDH del 24 de abril de 1990, caso Kruslin contra Francia, y del 25 de marzo de 1998, Kopp contra Suiza).

De la última exigencia se deriva que la ley debe emplear términos suficientemente claros para indicar a todos en qué circunstancias y bajo qué condiciones se habilita a los poderes públicos a tomar tales medidas. Ello supone el empleo de reglas claras y detalladas, que incluyan las siguientes garantías mínimas, referidas fundamentalmente a los supuestos de intervenciones telefónicas (entre otros, casos Malone, Kruslin, Kopp y Valenzuela Contreras, citados, y sentencia del 24 de abril de 1990, caso Huvig contra Francia):

a) La definición de las categorías de personas susceptibles de ser sometidas a vigilancia telefónica judicial. 
b) La naturaleza de las infracciones a que puedan dar lugar.

c) La fijación de un límite de la duración de la ejecución de la medida.

d) Las condiciones de establecimiento de los atestados que consignen las conversaciones interceptadas.

e) Las precauciones que se deben tomar para comunicar intactas y completas las grabaciones realizadas, con el fin de ser controladas eventualmente por el juez y la defensa.

f) Las circunstancias en las que se puede o debe realizar el borrado o la destrucción de dichas cintas, sobre todo tras el sobreseimiento o la absolución.

Con todos estos parámetros, el Tribunal de Estrasburgo ha valorado la adecuación de las normas previsoras de la intervención de las comunicaciones que se han sometido a su consideración, y en concreto en dos casos se ha referido a las previsiones contenidas en la Ley de Enjuiciamiento Criminal española. Así, en el ya mencionado asunto Valenzuela Contreras contra España, el TEDH, valorando unos hechos producidos en 1985, se pronunció sobre el requisito de la previsión legal en relación con la situación legal entonces existente, conformada fundamentalmente, además de por el artículo 18, inciso 3, de la Constitución, por el artículo 579 de la mencionada ley procesal en su redacción anterior a la reforma de $1988,{ }^{1}$ señalando que el conjunto de ambos artículos no permitía cumplir las condiciones derivadas del Convenio en cuanto a la previsibilidad de la ley, al no preverse con detalle suficiente las garantías que precisan la extensión y las modalidades del ejercicio del poder de apreciación de las autoridades. Sin embargo, posteriormente el TEDH ha vuelto a pronunciarse sobre hechos posteriores a la reforma del artículo 579 de la Ley de Enjuiciamiento Criminal llevada a cabo por la Ley Orgánica 4/1988, ${ }^{2}$ y así en

\footnotetext{
En esa redacción, el artículo 579 señalaba: «Podrá el juez acordar la detención de la correspondencia privada, postal y telegráfica que el procesado remitiere o recibiere y su apertura y examen, si hubiere indicios de obtener por esos medios el descubrimiento o la comprobación de algún hecho o circunstancia importante de la causa».

2 Esta es la redacción dada por dicha ley orgánica al artículo 579 de la Ley de Enjuiciamiento Criminal:

«1. Podrá el Juez acordar la detención de la correspondencia privada, postal y telegráfica que el procesado remitiere o recibiere y su apertura y examen, si hubiere indicios de obtener por estos medios el descubrimiento o la comprobación de algún hecho o circunstancia importante de la causa.

2. Asimismo, el Juez podrá acordar, en resolución motivada, la intervención de las comunicaciones telefónicas del procesado, si hubiere indicios de obtener por estos medios el descubrimiento o la comprobación de algún hecho o circunstancia importante de la causa. 3. De igual forma, el Juez podrá acordar, en resolución motivada, por un plazo de hasta tres meses, prorrogable por iguales períodos, la observación le las comunicaciones postales, telegráficas o telefónicas de las personas obre las que existan indicios de responsabilidad criminal, así como de las comunicaciones de las que se sirvan para la realización de sus fines delictivos.
} 
la sentencia del 18 de febrero de 2003, caso Prado Bugallo contra España, siguió considerando insuficientes las garantías de la legislación española, señalando que las reformas introducidas en 1988 no responden a todas las condiciones exigidas por la jurisprudencia del TEDH para evitar abusos, y que «[... $]$ lo mismo ocurre con la naturaleza de las infracciones que pueden dar lugar a las escuchas, con la fijación de un límite a la duración de la ejecución de la medida, y con las condiciones de establecimiento de las actas de síntesis que consignan las conversaciones intervenidas, tarea que se deja a la competencia exclusiva del secretario judicial». Con todo, el Tribunal comprueba que las insuficiencias existentes fueron paliadas en gran parte por la jurisprudencia posterior a aquellos hechos, en particular la del Tribunal Supremo — sentencia del 21 de febrero de 1991 y auto del 18 de junio de 1992-.

Quedaría, por tanto, la duda de si con esa integración jurisprudencial se cumplen actualmente las garantías del Convenio. Pero en todo caso parece imprescindible proceder a una nueva reforma del mencionado precepto de la Ley de Enjuiciamiento Criminal, sobre todo teniendo en cuenta que el Tribunal Constitucional, en sentencia 184/2003 del 23 de octubre - posterior al asunto Prado Bugallo, que expresamente se cita-, ha afirmado la insuficiencia del artículo 579 de la LECrim, señalando que este «[...] adolece de vaguedad e indeterminación en aspectos esenciales, por lo que no satisface los requisitos necesarios exigidos por el artículo 18, inciso 3, CE para la protección del derecho al secreto de las comunicaciones, interpretado, como establece el art. 10.2 CE, de acuerdo con el artículo 8, inciso 1, y artículo 2, CEDH», y destacando en particular:

[...] la insuficiencia de su regulación sobre el plazo máximo de duración de las intervenciones, puesto que no existe un límite de las prórrogas que se pueden acordar; la delimitación de la naturaleza y gravedad de los hechos en virtud de cuya investigación pueden acordarse; el control del resultado de las intervenciones telefónicas y de los soportes en los que conste dicho resultado, es decir, las condiciones de grabación, y custodia, utilización y borrado de las grabaciones, y las condiciones de incorporación a los atestados y al proceso de las conversaciones intervenidas. Por ello, hemos de convenir en que el art. 579 LECrim no es por sí mismo norma de cobertura adecuada, atendiendo a las garantías de certeza y seguridad jurídica, para la restricción del derecho fundamental al secreto de las comunicaciones telefónicas. (Artículo 18, inciso 3, CE).

4. En caso de urgencia, cuando las investigaciones se realicen para la averiguación de delitos relacionados con la actuación de bandas armadas elementos terroristas o rebeldes, la medida prevista en el número 3 de este artículo podrá ordenarla el Ministro del Interior o, en su defecto, el Director de la Seguridad del Estado, comunicándolo inmediatamente por escrito motivado al Juez competente, quien, también de forma motivada, revocará o confirmará tal resolución en un plazo máximo de setenta y dos oras desde que fue ordenada la observación». 
Con todo, estas y otras deficiencias legales señaladas por la jurisprudencia - por ejemplo, la falta de previsión de garantía alguna hacia el destinatario de la conversación telefónica en el caso de intervención de teléfonos-, que implica una vulneración del derecho por la omisión de la ley, no supone de forma ineludible que toda resolución judicial que acuerde la interceptación de las comunicaciones vulnere igualmente el derecho fundamental - lo que en la práctica supondría la imposibilidad de acordar ninguna interceptación hasta que no se reformase la ley-, pues los jueces podrían acordar una medida de este tipo con el cumplimento de una serie de requisitos que de alguna manera suplirían o complementarían, solo en el caso concreto, las carencias de la ley. En este sentido, el Tribunal Constitucional ha declarado que:

[...] si, pese a la inexistencia de una ley que satisficiera las genéricas exigencias constitucionales de seguridad jurídica, los órganos judiciales, a los que el art. 18.3 de la Constitución se remite, hubieran actuado en el marco de la investigación de una infracción grave, para la que de modo patente hubiera sido necesaria, adecuada y proporcionada la intervención telefónica y la hubiesen acordado respecto de personas presuntamente implicadas en el mismo, respetando, además, las exigencias constitucionales dimanantes del principio de proporcionalidad, no cabría entender que el Juez hubiese vulnerado, por la sola ausencia de dicha ley, el derecho al secreto de las comunicaciones telefónicas. [STC 49/ 1999, del 5 de abril, f. j. 5, STC 184/2003, del 23 de octubre, f. j. 6)].

Pero esto nos conduce ya a los restantes requisitos de la intervención legítima.

\subsection{El fin legítimo}

Desde el punto de vista constitucional, bastaría en principio una finalidad no contradictoria con la norma fundamental para adoptar una medida de interceptación de las comunicaciones, con el cumplimiento de los demás requisitos aplicables. Sin embargo, el mencionado artículo 8, inciso 2, del Convenio Europeo para la Protección de los Derechos Humanos y Libertades Fundamentales señala expresamente los objetivos o fines que puede perseguir la medida que constituya una injerencia en el derecho, para considerarse admisible. Estos fines son: la seguridad nacional, la seguridad pública, el bienestar económico del país, la defensa del orden y la prevención del delito, la protección de la salud o de la moral, o la protección de los derechos y las libertades de los demás.

Entre estos fines, cobra especial relevancia el de la persecución de los delitos. Nuestra jurisprudencia se refiere reiteradamente a la idea de investigación de una infracción grave, y en la práctica la mayoría de las interceptaciones de las comunicaciones se producen en el ámbito de procesos penales, de manera que es la Ley de Enjuiciamiento Criminal la que fundamentalmente cumple en nuestro sistema — si bien de forma deficiente, como se ha visto— el requisito de la 
previsión legal. En tales casos, la finalidad de la interceptación, en términos genéricos, podrá ubicarse con frecuencia en algunos de los valores mencionados en el artículo 8, inciso 2, del Convenio de Roma, como la defensa del orden y la prevención del delito. Pero desde luego no se trata del único ámbito en el que resulta admisible la interceptación, sino que cabe añadir cualquier otro que esté previsto en la ley y pueda reconducirse a algún fin legítimo. Así, por ejemplo, nuestra legislación penitenciaria prevé también otros supuestos de restricciones, suspensiones o intervenciones en las comunicaciones de los reclusos (artículo 51 LOGP y 41 y s(s) del Reglamento Penitenciario), que podrían vincularse a las finalidades de seguridad pública, defensa del orden o protección de los derechos de los demás.

\subsection{La necesidad en una sociedad democrática}

Como se ha visto, el Convenio europeo, al referirse a las injerencias admisibles en el derecho, requiere que estas sean medidas necesarias en una sociedad democrática. Esta expresión implica varias consecuencias:

1. La idoneidad, en el sentido de adecuación de la medida al fin legítimo perseguido, esto es, que la medida efectivamente tiende al objetivo perseguido.

2. La necesidad estricta o necesidad en sentido propio, que impide entender cumplido el requisito si se comprueba la existencia de otro medio que, suponiendo una menor injerencia en el derecho, tiende a conseguir idéntica finalidad.

3. En esta misma línea - y de hecho tiende a confundirse con el requisito anterior-, nuestra jurisprudencia prefiere utilizar más el criterio de la proporcionalidad, que podría entenderse simplemente como equilibrio entre medio y fin, sin que aquel resulte excesivo para la consecución del objetivo, esto es, que el sacrificio del derecho ha de ser proporcional al objetivo perseguido.

La jurisprudencia del Tribunal Europeo de Derechos Humanos sobre el requisito de la necesidad en una sociedad democrática es bastante amplia, pues son muy frecuentes los supuestos en los cuales, a pesar de entender que una concreta medida estaba prevista en la ley y perseguía un fin legítimo, no resultaba necesaria en una sociedad democrática. Solo entre los casos más recientes pueden mencionarse en esta línea las sentencias del 19 de abril de 2001, caso Peers contra Grecia; 24 de julio de 2001, caso Valainas contra Lituania; 11 de diciembre de 2003, caso Basani contra Italia; 24 de febrero de 2005, caso Jaskaukas contra Lituania. 
La jurisprudencia del Tribunal Constitucional español - y en similares términos la del Tribunal Supremo- ha acogido los criterios derivados del Convenio europeo - que es de obligada utilización para interpretar los derechos constitucionales de acuerdo con lo previsto en el artículo 10, inciso 2-, incorporando los requisitos establecidos por la jurisprudencia del Tribunal de Estrasburgo. De todas formas, como ya se ha apuntado, parece preferirse el término proporcionalidad al de necesidad, ya que aquel es un criterio general que el Tribunal Constitucional utiliza para la valoración de las medidas que puedan afectar a cualquiera de los derechos fundamentales, y que se interpreta como un equilibrio entre el sacrificio del derecho y el fin perseguido con la injerencia. Se entiende así que una medida está justificada solo cuando supone un sacrificio del derecho fundamental estrictamente necesario, y existe proporción entre la medida y el sacrificio.

En realidad, en ciertos casos parece deducirse que el requisito de proporcionalidad es un añadido al de necesidad, mientras que en otros supuestos se diría que la proporcionalidad sustituye en la interpretación del Tribunal Constitucional - y acaso flexibiliza - el requisito de la necesidad, o bien tiende incluso a englobar los requisitos de finalidad, idoneidad y necesidad. En esta línea, el TC ha afirmado que la observancia del principio de proporcionalidad supone que «[...] la autorización se dirige a alcanzar un fin constitucionalmente legítimo, como acontece en los casos en que se adopta para la investigación de la comisión de delitos calificables de graves y es idónea e imprescindible para la determinación de hechos relevantes para la misma (SSTC 49/1999, de 5 de abril, FJ 8; 299/2000, de 11 de diciembre, FJ 2)» (STC 184/2003, de 23 de octubre, f. j. 9). En otros casos más bien parece que existe una proporcionalidad en sentido amplio, que incluye todos los requisitos mencionados, y una proporcionalidad en sentido estricto, que es en definitiva el equilibrio entre medio y fin, y que viene a distinguirse del requisito más estricto de la necesidad, como cuando ha afirmado que

[...] del principio de proporcionalidad, cuya vigencia hemos reafirmado en el ámbito de las intervenciones telefónicas (SSTC 85/1994, fundamento jurídico 3; 181/1995, fundamento jurídico 5; 49/1996, fundamento jurídico 3; 54/ 1996, fundamento jurídico 7 y 123/1997, fundamento jurídico 4.), se infiere inmediatamente que, tanto la regulación legal como la práctica de las mismas ha de limitarse a las que se hallen dirigidas a un fin constitucionalmente legítimo que pueda justificarlas y que se hallan justificadas sólo en la medida en que supongan un sacrificio del derecho fundamental estrictamente necesario para conseguirlo y resulten proporcionadas a ese sacrificio. (STC 49/1999, del 5 de abril).

En fin, es a la proporcionalidad en sentido estricto a la que parece referirse el Tribunal Supremo cuando afirma que esta «[...] supone, en el tema que está 
en debate, que exista un correlato entre la medida, su duración, su extensión y las circunstancias del caso, especialmente la naturaleza del delito, su gravedad y su propia trascendencia social» (auto del Tribunal Supremo de 18 de junio de 1992).

\subsection{La resolución judicial: requisitos y excepciones a la autorización judicial previa}

El artículo 18, inciso 3, de la Constitución española garantiza el secreto de las comunicaciones «salvo resolución judicial», lo que viene a implicar la exigencia ineludible de intervención del juez para llevar a cabo una eventual interceptación de dichas comunicaciones. Ello es coherente con la idea, presente en el constitucionalismo contemporáneo, del Poder Judicial como garante de los derechos y como único legitimado para autorizar determinadas injerencias en los mismos. Y en definitiva, supone que será un juez quien, en cada caso concreto, deba analizar si se cumplen los requisitos hasta ahora apuntados — previsión legal, finalidad, necesidad—, y cabe por tanto autorizar la interceptación.

Precisamente por ello, el requisito de la resolución judicial no puede entenderse cumplido con la mera contrastación del dato formal de la existencia de dicha resolución, sino que la misma debe cumplir determinadas exigencias, que se derivan fundamentalmente de los requisitos ya conocidos para que la injerencia sea legítima, y que se han ido señalando por la jurisprudencia del TEDH, de nuestro Tribunal Constitucional y del Tribunal Supremo. En síntesis, esos requisitos serían los siguientes:

1) Motivación de la resolución judicial. Es un elemento imprescindible teniendo en cuenta que es la vía para que puedan conocerse los requisitos y las circunstancias por las que resulta admisible la injerencia en el derecho fundamental. Por esa misma razón, el requisito de la motivación no puede entenderse cumplido por la mera existencia formal de una fundamentación en la resolución judicial, sino que es necesario que esa motivación incorpore determinadas exigencias y cumpla a su vez con ciertos parámetros. En esta línea, la jurisprudencia ha señalado que:

a. La motivación ha de ser expresa, si bien puede integrarse con la solicitud policial, cuando el conjunto resultante cumpla todos los requisitos de la motivación. En todo caso, el Tribunal Constitucional ha advertido frente a los formularios que no encierran verdadera motivación.

b. La motivación debe expresar el criterio de proporcionalidad que justifica la intervención, esto es, el equilibrio entre la medida que se adopta y la finalidad perseguida. 
c. Debe precisarse el alcance de la medida, en qué va a consistir esta, cómo se llevará a cabo y cuáles serán sus límites.

d. En el caso de que la interceptación se acuerde en el curso de un proceso penal, la motivación debe exteriorizar los indicios existentes - y no meras sospechas—, así como el delito o delitos que se persiguen y, en su caso, las personas sobre las que recaigan dichos indicios.

2) Establecimiento de un plazo. Este plazo empezará a contar desde la aprobación del auto judicial, no desde su ejecución y efectiva intervención (STC 205/2005, del 18 de julio).

3) La intervención debe referirse a personas concretas y determinadas, y respecto a delitos también concretos. No es admisible la disociación entre la autorización y la investigación posterior. Tampoco caben las autorizaciones genéricas, ni «[...] es correcto mantener la intervención/observación cuando se descubre que el nuevo y presunto delito que se dibuja por la telefonía es independiente del que fue objeto de la inicial autorización» (auto del TS del 18 de junio de 1992).

4) Una vez terminada la observación o intervención, debe comunicarse a los afectados.

Como se deduce de lo anterior, la resolución judicial que autoriza la interceptación se produce con carácter general de forma previa a que se produzca la efectiva interceptación, lo cual tiende a garantizar que no se produzcan extralimitaciones que impliquen lesión del derecho. Sin embargo, y de forma excepcional, se permite que la intervención judicial sea posterior en determinados supuestos. Son los siguientes:

1. La intervención o suspensión de las comunicaciones de los reclusos, prevista en los artículos ya mencionados de la legislación penitenciaria. Según esta legislación, esta interceptación puede acordarse de forma motivada por el Director del establecimiento, dando cuenta al Juez de Vigilancia Penitenciaria. Sobre este particular, pueden verse las SSTC 128/1997, de 14 de julio, y 106/2001, de 23 de abril. Con todo, ha de señalarse que existe a su vez una excepción a la excepción, consistente en que las comunicaciones del recluso con el abogado - en las que además del secreto de las comunicaciones está en juego el derecho de defensa, tal y como ha reiterado la jurisprudencia - sí requieren una previa autorización judicial para ser intervenidas.

2. En el caso de suspensión de los derechos como consecuencia de la declaración de los estados de excepción o sitio, es posible una interceptación que podríamos denominar "preventiva» de las comunicaciones, si resulta necesario 
para el esclarecimiento de hechos presuntamente delictivos o el mantenimiento del orden público; en todo caso, se requiere que se comunique inmediatamente la misma por escrito al juez (artículo 55, inciso 1, de la Constitución, Ley Orgánica 4/1981, del 1 de junio).

3. En el supuesto de suspensión individual de los derechos relacionada con la investigación de bandas armadas o elementos terroristas (artículo 55, inciso 2, $\mathrm{CE}$ ), cabe la intervención previa, acordada por el Ministro del Interior o el Director General de Seguridad del Estado, dando cuenta al juez, quien, de forma motivada, revocará o confirmará la resolución en el plazo de 72 horas (artículo 579, inciso 4, LECrim).

\section{Efectos de la interceptación ilícita}

Por tanto, toda interceptación que incumpla los requisitos que hemos ido senalando, será ilegítima en nuestro ordenamiento jurídico, suponiendo una vulneración del derecho al secreto de las comunicaciones. Ello implica una serie de consecuencias, como, en su caso, la sanción penal para los responsables de la interceptación, en los términos previstos en el Código Penal.

Pero ahora interesa destacar principalmente una consecuencia procesal de trascendencia, como es la nulidad de cualquier prueba que hubiera podido obtenerse como consecuencia de la interceptación ilegítima. Esta consecuencia, que ha sido reiterada por la jurisprudencia —así, por ejemplo, SSTC 114/ 1984, del 29 de noviembre; 81/1998, del 2 de abril; 49/1999, del 5 de abril; 299/2000, del 11 de diciembre; 184/2003, del 23 de octubre—, deriva, según el Tribunal Constitucional, de la posición preferente de los derechos fundamentales, de su condición de inviolables, y de la necesidad institucional de no confirmar, reconociéndoles efectividad, sus contravenciones (STC 49/1999, f. j. 12). Lo contrario implicaría, además, la vulneración del derecho a un proceso con todas las garantías, y, en su caso, de la presunción de inocencia si se produjera la condena penal basándose en una prueba que es inválida.

Más difícil resulta precisar los concretos efectos que esta invalidez puede tener sobre otras pruebas y sobre otros actos procesales que de alguna manera se vinculan a la prueba obtenida ilícitamente. En este sentido, el Tribunal Constitucional ha señalado que la nulidad de la prueba ilícita arrastra a aquellas otras que son consecuencia de la misma, pero que dicha consecuencia debe entenderse en términos de conexión de antijuridicidad más que como una mera relación natural de consecuencia, de forma que pueden resultar excepcionalmente admisibles aquellas pruebas que, pese a resultar del conocimiento adquirido a través de la prueba ilícita, son jurídicamente independientes de esta (SSTC 86/1995, del 6 de junio; 54/1996, del 26 de marzo; 81/1998, del 2 de abril). 


\section{Las garantías del derecho al secreto de las comunicaciones}

Como derecho fundamental, reconocido en la sección primera del capítulo II del título I, el derecho al secreto de las comunicaciones forma parte del bloque de derechos a los que la Constitución dispensa el máximo nivel de protección, contando con las siguientes garantías:

1. Debe ser desarrollado por ley orgánica (artículos 53, inciso 1 y 81, inciso 1 CE)

2. La ley debe respetar su «contenido esencial» (artículo 53, inciso 1)

3. Debe estar protegido por un procedimiento preferente y sumario ante los tribunales ordinarios (artículo 53, inciso 2)

4. Es susceptible de amparo ante el Tribunal Constitucional (artículo 53, inciso 2)

5. Su reforma debe seguir el procedimiento agravado (artículo $168 \mathrm{CE}$ )

Además, y por su simple inclusión entre los derechos recogidos en la Carta Magna, el derecho se puede tutelar a través del recurso y la cuestión de inconstitucionalidad (artículo 53, inciso 1, 161.1ª y $163 \mathrm{CE}$ ), y por el Defensor del Pueblo (artículo $54 \mathrm{CE}$ ). Por lo demás, como parte del sistema de derechos fundamentales, debe presidir la interpretación de todo el ordenamiento jurídico, de manera que las normas deben interpretarse de la forma más favorable a su ejercicio.

En fin, más allá de la Constitución, otras leyes, y en particular el Código Penal, establecen otras garantías específicas para este derecho.

\section{Jurisprudencia}

\subsection{Tribunal Europeo de Derechos Humanos}

- Sentencia del 6 de septiembre de 1978, caso Klass contra Alemania

- Sentencia del 2 de agosto de 1984, caso Malone contra el Reino Unido

- Sentencia del 24 de abril de 1990, caso Kruslin contra Francia

- Sentencia del 24 de abril de 1990, caso Huvig contra Francia

- Sentencia del 30 de julio de 1997, caso Valenzuela Contreras contra España

- Sentencia del 25 de marzo de 1998, caso Kopp contra Suiza

- Sentencia del 19 de abril de 2001, caso Peers contra Grecia

- Sentencia del 24 de julio de 2001, caso Valainas contra Lituania

- Sentencia del 18 de febrero de 2003, caso Prado Bugallo contra España

- Sentencia del 11 de diciembre de 2003, caso Basani contra Italia

- Sentencia del 24 de febrero de 2005, caso Jaskaukas contra Lituania 


\subsection{Tribunal Constitucional}

- STC 114/1984, del 29 de noviembre

- STC 86/1995, del 6 de junio

- STC 54/1996, del 26 de marzo

- STC 128/1997, del 14 de julio

- STC 81/1998, del 2 de abril

- STC 49/1999, del 5 de abril

- STC 299/2000, del 11 de diciembre

- STC 202/2001, del 15 de octubre

- STC 106/2001, del 23 de abril

- STC 70/2002, del 3 de abril

- STC 123/2002, del 20 de mayo

- STC 184/2003, del 23 de octubre

- STC 205/2005, del 18 de julio

\section{Bibliografía}

Belda Pérez-Pedrero, E. «El derecho al secreto de las comunicaciones». En Parlamento y Constitución, no 2, 1998.

De Llera SuÁreZ-BÁrCEnA, E. «El régimen jurídico de las observaciones telefónicas en el proceso penal». En Poder Judicial, no 3, 1986.

FERnÁndez García, J.J. «Inviolabilidad y secreto de la correspondencia». En Revista Española de Derecho Administrativo, no 39, 1983.

JimÉnEZ CAMPO, J. «La garantía constitucional del secreto de las comunicaciones». En Revista Española de Derecho Constitucional, no 20, 1987.

LÓpez BARJA DE QUIROGA, J. Las escuchas telefónicas y la prueba ilegalmente obtenida. Madrid: Akal, 1989.

López-Fragoso Álvarez, T. Las intervenciones telefónicas en el proceso penal. Madrid: Colex, 1991.

Martín Morales, M. El régimen constitucional del secreto de las comunicaciones. Madrid: Civitas, 1995.

Montañés Pardo, M. A. La intervención de las comunicaciones. Pamplona: Aranzadi, 2000.

Rafols Llach, J. «Autorización judicial para la instalación de aparatos de escucha, transmisión y grabación en lugar cerrado». En Cuadernos de Derecho Judicial, Madrid, 1992.

Rodríguez Ruiz, B. El secreto de las comunicaciones (tecnología e intimidad). Madrid: McGraw Hill, 1997. 